\title{
Measurement of Disability and Its Predictors Among Trauma Patients: A Follow-up Study
}

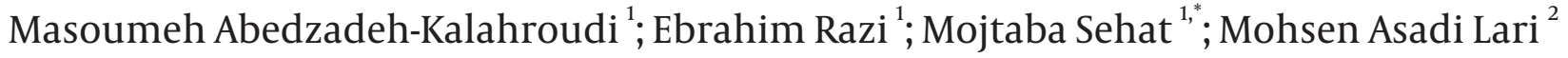 \\ ${ }^{1}$ Trauma Research Center, Kashan University of Medical Sciences, Kashan, IR Iran \\ 2 School of Public Health, Tehran University of Medical Sciences, Tehran, IR Iran \\ ${ }^{*}$ Corresponding author: Mojtaba Sehat, Trauma Research Center, Kashan University of Medical Sciences, Kashan, IR Iran. Tel: +98-3155620634, E-mail: om_sehat@yahoo.com
}

Received: April 22, 2015; Revised: May 30, 2015; Accepted: June 9, 2015

\begin{abstract}
Background:Globally more than a billion people, $15 \%$ of the population, lives with disability and most of disabilities are caused by injuries. Objectives: The aim of this study was to describe the prevalence of disability and its predictors at 1 and 3 months post-injury in Kashan City during 2014- 2015.

Patients and Methods: In this longitudinal follow-up study, 400 injured patients 15 - 65 years referred to Shahid Beheshti hospital in Kashan and hospitalized more than 24 hours were assessed for disability status with the WHODAS II 12-item instrument at 1 and 3-months post-injury. Patients based on their disability scores were divided into 5 groups: none, mild, moderate, severe and very severe. Work status was assessed at the 3-month follow-up with one question "Are you back at work following your injury". Also, demographic characteristics and information about injury were gathered by a checklist. Data were analyzed using chi-square, Mann-Whitney U, Kruskal Wallis, Pearson correlation coefficient and logistic regression by SPSS software. The significance level was set at $\mathrm{P}<0.05$.

Results: The mean disability scores at 1 and 3 months post-injury was $30.3(9.2)$ and 18.8 (8.3), respectively and there was a statistical significant difference between disability status at 1 and 3 months after trauma $(\mathrm{P}<0.0001)$. The rates of return to work in 262 employed patients at 1 and 3 months after injury were $29 \%$ and $55.4 \%$, respectively. The disability score showed a statistically significant correlation with Injury Severity Score (ISS) $(\mathrm{P}<0.0001)$, work return $(\mathrm{P}=0.033)$, intensive care unit transfer $(\mathrm{P}<0.0001)$, trauma type $(\mathrm{P}=0.001)$ and age $(\mathrm{P}=0.004)$. Also, age, ISS, duration of hospital stay and injury to extremities were predictors of disability.

Conclusions: More than half of the patients were disabled after 3 months of trauma. Elderly patients, patient with severe trauma, and long hospitalization and patients with extremity injuries were high risk for disability.
\end{abstract}

Keywords: Injury; Return to Work; Disability Evaluation; Injury Severity Score

\section{Background}

Worldwide more than a billion people, $15 \%$ of the population, live with disability and most of disabilities are caused by injuries due to traffic accidents, violence, falls, burns and assault (1). World Health Organization (WHO) in report of global burden of disease predicts by 2020 , trauma will responsible for 1 in 5 life-years lost around the world (2).

Based on WHO definition Disabilities is an umbrella term, covering impairments, activity limitations, and participation restrictions. Impairment is a problem in body function or structure; activity limitation is a difficulty encountered by an individual in executing a task or action; while a participation restriction is a problem experienced by an individual in involvement in life situations. Thus, disability is a complex phenomenon, reflecting an interaction between features of a person's body and features of the society in which he or she lives (3).

Prevalence of disability and its predictors are varied based on study population, type of injury, type of disabilities including psychological or physical, time of patient follow-up and disability assessment tools.
In a study by Vles et al. on 295 patients, more than 50\% of patients had problems in daily activities one year after trauma. Also, 74\% (84) of 127 patients in working age had returned to work. The number of organ injured, Injury Severity Score(ISS) $\geq 25$, and femalegenderwere independent predictors of long-term disability (4). Another study by Richmond et al. on 109 patients at 3 months after discharge showed that most of patients had severe disability and moderate psychological distress. Extremity injuries, low education level, and high level of posttraumatic distress were predictors of severe disability (5).

Study by Baldry Currens on 201 trauma patients at 12 months post-injury showed that more than $80 \%$ of patients were independent in Functional Independence Measure (FIM) domains and 69.2\% had returned to work. Sever injuries and injury to head and spinal cord showed the poorest functional outcomes (6).

In a longitudinal cohort study, O’Donnell et al. assessed disability at 12 months post-injury in 715 patients by world health organization disability assessment schedule II (WHODAS II). They found that mean and SD of dis-

Copyright (C) 2015, Kashan University of Medical Sciences. This is an open-access article distributed under the terms of the Creative Commons Attribution-NonCommercial 4.0 International License (http://creativecommons.org/licenses/by-nc/4.0/) which permits copy and redistribute the material just in noncommercial usages, provided the original work is properly cited. 
Abedzadeh-Kalahroudi M et al.

ability score was $21.6 \pm 19.7$ and disability at this time was 4 times greater than general population (7). In Ringburg et al. study, prevalence of functional limitation one year after injury was 40\% - 70\% and female sex and comorbidity were predictors of disability (8).

Factors predicting functional outcome are controversial, although several studies have shown that intensive care unit (ICU) stay duration (9), high ISS $(4,10)$, low level of education (5), age $(11,12)$, female sex $(4,8)$, number of organ injured (4), hospital complications (13), previous quality of life (12), injury to the extremity, spinal cord or brain $(4,6,9,14)$ were risk factors of disability.

Despite a high prevalence of trauma in Iran, based on our knowledge there are not enough data on the prevalence of disability among trauma patients. Disability measurement after trauma is an important component of trauma care system and can provide information about the need for rehabilitation.

\section{Objectives}

The aim of this study was to determine the prevalence of disability and its predictors at 1 and 3 months post-injury in Kashan City, Iran, during 2014 - 2015.

\section{Patients and Methods}

\subsection{Study Design}

This longitudinal follow-up study was conducted on trauma patients hospitalized in Shahid Beheshti hospital, the only center that provides medical care for trauma patients in Kashan, Iran. Kashan County is located in central part of Iran with 400,000 populations. The rate of adult injury in Kashan is about 1245 per 100,000 population per year (15) that is higher than the worldwide rate of 61 per 100,000 population (16).

\subsection{Subjects}

Due to lack of information about the prevalence of disability in trauma patients, sample size was calculated based on a pilot study on 20 patients and showed that about $42 \%$ of patients have some degree of disability postinjury. Based on the formula $\left(\mathrm{z}^{2} \mathrm{pq} / \mathrm{d}^{2}\right) 370$ subjects were calculated $(\alpha=5 \%, d=0.05$ and $P=0.42)$; however, for possible attrition 400 patients were entered to the study. The inclusion criteria were: age range of 15 - 65 years, no history of physical or mental disability, hospitalization more than 24 hours due to trauma, and residing in Kashan county. Patients who died or were not available during a follow-up period were excluded from the study.

\subsection{Measurement}

A three-section questionnaire was used in this study. The first section of this questionnaire included questions regarding demographic characteristics such as age, sex, place of residence, nationality, level of education, marital status and patient job. The second section included information about injury characteristics such as mechanism of injury, place of injury, injured organ, type and nature of trauma, ISS, Revised Trauma Score (RTS), Glasgow Coma Scale (GCS), ICU transfer and duration of ICU and hospital stay. The third section was WHODAS II-12 item for measuring disability. This questionnaire is a valid and reliable tool for disability assessments in different populations (15) and validity and reliability of this questionnaire also were confirmed in our pilot study. The WHODAS II measures disability across 6 domains: 1) understanding and communication, 2) getting around,3) self-care, 4) getting along with others, 5) life activities, and 6) participation in society. This questionnaire contains 12 items in Likert scale from 1 (no disability) to 5 (very severe disability) scores and measured the disability level during one month ago (15). Minimum and maximum scores were 12 and 60 and obtained disability scores were converted to a 0 - 100 scale. The higher score indicated the higher disability. Also, work status was assessed at the 3-month follow-up with one question "Are you back at work following your injury?".

Patients were evaluated for disability status with the brief WHODAS II 12-item instrument at 1 and 3 months post-injury. They were divided into 5 groups based on their disability score: none (score 0 - 4), mild (score 5-25), moderate (score 26 - 50), severe (score 51 - 75) and very severe (score 76 - 100). Also, in some statistical analysis, we used mean and SD of total disability score. Based on trauma severity, patients were divided into four groups: mild (ISS < 9), moderate (ISS = 9-15), severe (ISS = 16-24) and very severe (ISS $>25$ ).

All data were gathered by interviewing patients or their family members (if patient was not alert) and referring to their medical records at the hospital. Also, the first author assessed patients' level of disability by using the 12-item WHODAS II at 1 and 3 months post-discharge by a telephone interview.

\subsection{Statistical Analysis}

Data were analyzed using SPSS 17 software. Normal distribution of data was assessed by Kolmogorov-Smirnov test. We used chi-square test to assess a disability level at 1 and 3 months post-injury; Mann-Whitney U and KruskalWallis tests were also used to compare the mean disability score within different subgroups according to data distribution. Moreover, a Pearson correlation coefficient was used to assess correlation between disability score and quantitative variables. Multiple regression analysis was used to show disability predictors. The significance level was set at P Value $<0.05$.

\subsection{Ethical Consideration}

This study was approved by the ethics committee of Kashan university of medical sciences and all patients were signed an informed consent and assured for information confidentiality. 


\section{Results}

Mean age of the participants was $34.4(\mathrm{SD}=14.6)$ years. In total, $84.2 \%$ of the participants were male, $81.5 \%$ lived in urban area, $89.2 \%$ were Iranian, $61.2 \%$ were under diploma, $65.5 \%$ were employee and $62.5 \%$ were married. Table 1 shows that traffic-related injuries were responsible for $64.8 \%$ of injuries that most of them ( $81.2 \%$ ) were motor vehicle accidents. Fifty percent of the patients had multiple traumas, $85.2 \%$ had blunt trauma and $81.8 \%$ had injuries in extremities.

Result showed that $44.2 \%$ of the cases had no disability after 3 months of hospital discharge and 223 of the cases (55.8\%) had some degree of disability (Table 2 ). The mean values (SD) of disability scores at 1 and 3 months postinjury were 30.3 (9.2) and 18.8 (8.3), respectively. According to disability domains, mean (SD) of disability score in activity limitation domain was 11.3 (15.8) and in participation domain was 16.9 (20.2).

Rates of RTW in 262 employed patients at 1 and 3 months after injury were $29 \%$ and $55.4 \%$, respectively. The mean (SD) of RTW time at 3 months was 63.4 (19.9) day.

\begin{tabular}{|c|c|}
\hline Variables & Values \\
\hline ISS & $10.1 \pm 6.5$ \\
\hline GCS & $14.6 \pm 1.2$ \\
\hline RTS & $7.7 \pm 0.3$ \\
\hline Length of hospital stay, d & $5.6 \pm 6.3$ \\
\hline ICU admission, \% & 6.8 \\
\hline Length of ICU stay, d & $7.4 \pm 7.3$ \\
\hline \multicolumn{2}{|l|}{ Mechanism of injury } \\
\hline Traffic-related & 64.8 \\
\hline Home-related & 13.5 \\
\hline Work-related & 12.5 \\
\hline Assault & 3.5 \\
\hline Others & 5.6 \\
\hline \multicolumn{2}{|l|}{ Organ injured } \\
\hline Extremities & 81.1 \\
\hline Head & 35.2 \\
\hline Abdomen & 3.2 \\
\hline Thorax & 8 \\
\hline spinal & 13 \\
\hline \multicolumn{2}{|l|}{ Trauma type } \\
\hline Single organ & 60 \\
\hline Multiple organ & 40 \\
\hline \multicolumn{2}{|l|}{ Nature of trauma } \\
\hline Sharp & 9.5 \\
\hline Blunt & 85.2 \\
\hline Both & 5.2 \\
\hline Disability score at 1 month & $30.3 \pm 9.2$ \\
\hline Disability score at 3 months & $18.8 \pm 8.3$ \\
\hline RTW at 1 month postinjury & 29 \\
\hline RTW at 3 months postinjury & 55.4 \\
\hline
\end{tabular}

There was a statistical significant difference between disability status at 1 and 3 months after trauma $(\mathrm{P}<$ 0.0001). Univariate analyses showed a statistically significant difference between disability score and ISS $(\mathrm{P}<$ 0.0001), work return $(P=0.033)$, ICU transfer $(P<0.0001)$, trauma type $(\mathrm{P}=0.001)$ and age $(\mathrm{P}=0.004)$ in trauma patients (Table 3 ).

\begin{tabular}{lccc}
\hline \multicolumn{4}{l}{ Table 2. Disability Level at One and Three Months Post-Injury } \\
\hline $\begin{array}{l}\text { Level of } \\
\text { Disability }\end{array}$ & At 1 Month & At 3 Months & P Value \\
\hline None & - & $177(44.2)$ & 0.0001 \\
Mild & $133(33.2)$ & $144(36)$ & \\
Moderate & $157(39.2)$ & $59(14.8)$ & \\
Severe & $104(26)$ & $18(4.5)$ & \\
Very severe & $6(1.5)$ & $2(0.5)$ & \\
Total & $400(100)$ & $400(100)$ & \\
\hline
\end{tabular}

${ }^{\mathrm{a}}$ Data are presented as No.(\%).

Table 3. Difference of Mean (Standard Deviation) World Health Organization Disability Assessment Schedule WHODAS II Score Based on Demographic and Injury Characteristics, 3 Months Post-injury ${ }^{\mathrm{a}}$

\begin{tabular}{|c|c|c|c|}
\hline Variables & Values ${ }^{b}$ & $\begin{array}{l}\text { WHODAS II } \\
\text { Score }^{c}\end{array}$ & PValue \\
\hline RTW & & & 0.033 \\
\hline No & $83(44.6)$ & $30.4 \pm 20.0$ & \\
\hline Yes & $103(55.4)$ & $6.02 \pm 9.2$ & \\
\hline Trauma severity & & & $<0.0001$ \\
\hline Mild, ISS < 9 & $228(57)$ & $9.9 \pm 13.7$ & \\
\hline Moderate, ISS $=9-15$ & $119(29.8)$ & $13.2 \pm 14.3$ & \\
\hline Severe, ISS = 16 - 24 & $29(7.2)$ & $31.9 \pm 20.5$ & \\
\hline Very Severe, ISS > 25 & $24(6)$ & $35.2 \pm 24.1$ & \\
\hline Gender & & & 0.35 \\
\hline Male & $337(84.3)$ & $13.7 \pm 17.6$ & \\
\hline Female & $63(15.7)$ & $15.9 \pm 15.3$ & \\
\hline Nationality & & & 0.1 \\
\hline Iranian & $357(89.2)$ & $14.5 \pm 17.3$ & \\
\hline Non Iranian & $43(10.8)$ & $11.4 \pm 17.1$ & \\
\hline ICU Transfer & & & $<0.0001$ \\
\hline No & $371(92.8)$ & $12.9 \pm 15.9$ & \\
\hline Yes & $29(7.2)$ & $30.4 \pm 25.5$ & \\
\hline Trauma Type & & & 0.001 \\
\hline Single organ & $240(60)$ & $11.7 \pm 14.2$ & \\
\hline Multiple organ & $160(40)$ & $17.7 \pm 20.6$ & \\
\hline Age, $y$ & & & 0.004 \\
\hline $15-24$ & $115(28.8)$ & $9.9 \pm 14.4$ & \\
\hline $25-34$ & $111(27.8)$ & $12.8 \pm 16.2$ & \\
\hline $35-44$ & $66(16.5)$ & $18.2 \pm 21.3$ & \\
\hline $45-54$ & $51(12.8)$ & $15.9 \pm 16.4$ & \\
\hline$>55$ & $57(14.2)$ & $18.5 \pm 18.3$ & \\
\hline \multicolumn{4}{|c|}{$\begin{array}{l}\text { Abbreviations: ICU, intensive care unit; RTW, return to work; SD, } \\
\text { standard deviation; WHODAS, world health organization disability } \\
\text { assessment schedule. } \\
\text { b Data are presented as No. (\%). } \\
\text { c Data are presented as mean } \pm \text { SD. }\end{array}$} \\
\hline
\end{tabular}


Abedzadeh-Kalahroudi M et al.

\begin{tabular}{|c|c|c|c|c|c|c|}
\hline & \multirow[t]{2}{*}{ Beta } & \multirow[t]{2}{*}{ Wald } & \multirow[t]{2}{*}{ P Value } & \multirow[t]{2}{*}{ OR } & \multicolumn{2}{|c|}{ 95\% CI for OR } \\
\hline & & & & & Lower & Upper \\
\hline ISS & 0.159 & 20.508 & 0.000 & 1.173 & 1.095 & 1.256 \\
\hline Age, $y$ & 0.022 & 6.444 & 0.011 & 1.022 & 1.005 & 1.040 \\
\hline Gender & -0.354 & 1.160 & 0.282 & 0.702 & 0.368 & 1.337 \\
\hline Number of injured organ & 0.474 & 1.532 & 0.216 & 1.606 & 0.759 & 3.399 \\
\hline Trauma type & -0.005 & 0.000 & 0.990 & 0.995 & 0.425 & 2.326 \\
\hline Number of surgery & 0.253 & 1.329 & 0.249 & 1.288 & 0.837 & 1.982 \\
\hline Length of hospital stay & 0.124 & 8.733 & 0.003 & 1.132 & 1.043 & 1.229 \\
\hline ICU admission & -0.585 & 0.572 & 0.449 & 0.557 & 0.122 & 2.539 \\
\hline Education & 0.354 & 1.905 & 0.168 & 1.425 & 0.862 & 2.356 \\
\hline Extremity injury & 0.895 & 5.061 & 0.024 & 2.448 & 1.122 & 5.340 \\
\hline Constant & -3.273 & 7.174 & 0.007 & 0.038 & & \\
\hline
\end{tabular}

a Abbreviations: ISS, injury severity score; CI, Confidence Interval; OR, Odds Ratio.

Pearson correlation coefficient showed a statistical correlation between disability and length of ICU stay ( $\mathrm{r}$ $=0.45$ and $\mathrm{P}=0.02)$, and hospital stay duration $(\mathrm{r}=0.47$ and $\mathrm{P}<0.0001)$.

Logistic regression analyses showed that age $(\mathrm{P}=0.011$, OR = 1.02), ISS $(P<0.0001, \mathrm{OR}=1.17)$, length of hospital stay $(\mathrm{P}=0.003, \mathrm{OR}=1.13)$ and injury to extremities $(\mathrm{P}=$ $0.024, \mathrm{OR}=2.44$ ) were predictors of disability (Table 4 ).

\section{Discussion}

Findings of the present study demonstrated that one month after trauma $72.4 \%$ of the participants had mild and moderate disability. Also, $55.8 \%$ of the cases had some degree of disability at 3 months post-injury. This finding is higher than Hetherington et al. study (16) that $21 \%$ of patients had disability at 6 months post-injury. Reason for this discrepancy is a longer follow-up period (6 months) in their study. This rate in Evans et al. (17) study was 80\% and in Ringburg et al. (8) study was $60 \%$ at one year after trauma that is higher than our rate and may be due to differences in the follow-up period and patient selection criteria. They had selected patients with major trauma; therefore, higher disability is expected but we included all minor and major trauma patients.

Finding of this study demonstrated that $56.5 \%$ of patients were less than 35 years old. This is an important issue because they are at working age and injury-related disability among them associated with financial and social problems due to employment difficulties. In O'Donnell et al. study (7) this rate was about $40 \%$ that is lower than our rate and may be due to the young population of Iran.

Our study showed that $29 \%$ of employed patients (76/262) had return to work at 1 month post-injury while this rate increased to $55.4 \%(103 / 186)$ at 3 months. This finding was lower than the reported rate of Langley et al. study (18) in which $68 \%$ of the patients returned to work at 3 months after trauma and Holtslag et al. study (19) that $79.9 \%$ of patients had RTW either to part or to fulltime work. The reason for a higher rate of RTW in these studies may be due to difference in follow-up time, for example in Holtslag et al. study, RTW was assessed at 15 months post-injury. On the other hand, Kendrick et al. (20) showed that $35 \%$ of patients at one month and $57 \%$ at four months after injury had fully RTW that is similar to our findings.

The results showed that mean and SD of disability score were lower in patients who had RTW at 3 months after injury and the difference was statistically significant $(\mathrm{P}<$ 0.0001). Our findings were also consistent with those of a study by Kendrick et al. showed that patients who had not RTW at 1 and 4 months post-injury had higher disability (20).

In present study, only $13.2 \%$ of the patients had major trauma (ISS $\geq 16$ ). The mean and SD of disability score in patients with severe and very severe trauma (ISS $\geq 16$ ) were higher than other groups (ISS $<16$ ) and differences were statistically significant $(\mathrm{P}<0.0001)$. Several studies have shown that functional outcome was related to ISS (4, $10,21)$. This issue represents that even patients with minor or moderate trauma can experience functional limitations postinjury and need more attention.

In our study, there was no significant difference between male and female patients in term of disability, which is consistent with the results of several studies (4, $22,23)$. Two studies have found that female gender is predictive for long-term disability after major trauma $(8,11)$; however, Rainer et al. study showed that male patients had higher disability (21). This controversy may be caused by the difference in the number of injured women, severity of trauma, assessment tools or study population.

Patients who had transferred to ICU and patients with 
multiple injuries had higher disability scores than other group and the difference was significant. The reason of this issue is higher ISS in ICU or multiple trauma patients. Old patient (age $>55$ year) had higher disability scores and young patients (age $<24$ year) had lower disability scores. This finding is compatible with Gabbe et al. study in which old patient had higher functional limitations after trauma (11).

Risk for post-injury disability is related to some demographic and injury-specific factors. In this study like other studies $(4,10,14,19)$, injury severity was predictive of disability. This finding shows ISS not only use as a criterion for predicting morbidity and mortality, but also can be used as a criterion to predict disability. However Richmond et al. (5) in their study reported that ISS is not a significant predictor of functional disability. This discrepancy may be due to difference in study population or disability assessment tools.

Injury to the extremities was another predictor of functional limitation. This finding is compatible with results of other studies like Richmond et al. (5), Holbrook et al. (9) and Aitken et al. (24). Considering that extremities were the most injured organs (81.1\%) in our study population, these patients need more attention after hospital discharge.

Another predictors of disability in our study was length of hospital stay that was similar with Holbrook et al. study (9). It is obvious that longer hospitalization is related to patient age, injury severity, number of injured organs, extremity injury, having surgery and comorbidity and some of these factors were associated with disability in our study.

Similar to other studies $(11,12,24)$, functional limitations increased with increasing age; therefore, older patients encountered with higher disability.

This study was the first follow-up study to our knowledge to investigate the short-term disability after injury in Iran and to use the WHODAS II- 12 item for assessment. Comparison between our findings and other studies was difficult due to the difference in disability assessment tools, study population, time of follow-up and other inclusion criteria.

Our study had some limitations. The lack of pre-injury disability status of trauma patients or general population in Iran was the first limitation. This is a general problem in outcome trauma assessment. The second limitation was a short-term follow-up period (one and three months).

Strengths of our study were the use of a simple, short, reliable and validate tool for measuring disability, assessment of return to work as an objective evidence of disability, evaluation of RTW and disability status at two time periods, and No sample loss during follow-up period. Moreover, in our study all trauma patients, regardless of the organ injured, type of injury or other characteristics were studied but some studies have focused on disability evaluation after specific injuries (brain trauma or spinal cord injury), or specific age (children or young adults) and others have focused on major and multiple injuries.

In conclusion, considering that more than half of the patients were disabled after 3 months of trauma, this information may help in organizing short- and longterm follow-up and rehabilitation programs in trauma patients. Determinants of functional outcome should be recognized and these patients need more attention during a recovery period.

\section{Acknowledgements}

This study is a part of the PhD dissertation supported by deputy of research, Kashan University of Medical Sciences (grant no: 9303). We also express our thanks to staff of trauma research center and Kashan Shahid Beheshti hospital for their cooperation.

\section{Authors' Contributions}

Masoumeh Abedzadeh-Kalahroudi contributed to searching the literature, data gathering and writing the first draft, results and their interpretation. Ebrahim Razi was responsible for study concept and supervised the study. Mojtaba Sehat contributed to analyzing the results and their interpretation. Mohsen Asadi-Lari made critical revision of the paper for important intellectual content.

\section{Funding/Support}

This study was financially supported by deputy of research at Kashan University of Medical Sciences (grant no: 9303).

\section{References}

1. World Health Organization .Injury-related disability and rehabilitation. WHO; 2014. Available from: http://www.who.int/violence_ injury_prevention/disability/en/.

2. World Health Organization . The global burden of disease: 2004 update.Geneva: World Health Organization; 2008.

3. Disabled World. Definitions of Disability. 2009. Available from: http://www.disabled-world.com/definitions/disability-definitions.php.

4. Vles WJ, Steyerberg EW, Essink-Bot ML, van Beeck EF, Meeuwis JD, Leenen LP. Prevalence and determinants of disabilities and return to work after major trauma. J Trauma. 2005;58(1):126-35.

5. Richmond TS, Kauder D, Schwab CW. A prospective study of predictors of disability at 3 months after non-central nervous system trauma.J Trauma.1998;44(4):635-42.

6. Baldry Currens JA. Evaluation of disability and handicap following injury. Injury. 2000;31(2):99-106.

7. O'Donnell ML, Varker T, Holmes AC, Ellen S, Wade D, Creamer M, et al. Disability after injury: the cumulative burden of physical and mental health. J Clin Psychiatry. 2013;74(2):e137-43.

8. Ringburg AN, Polinder S, van Ierland MC, Steyerberg EW, van Lieshout EM, Patka P, et al. Prevalence and prognostic factors of disability after major trauma. J Trauma. 2011;70(4):916-22.

9. HolbrookTL, Anderson JP, Sieber WJ, Browner D, Hoyt DB. Outcome after major trauma: discharge and 6-month follow-up results from the Trauma Recovery Project. J Trauma.1998;45(2):315-23.

10. Soberg HL, Bautz-Holter E, Roise O, Finset A. Long-term multidimensional functional consequences of severe multiple injuries two years after trauma: a prospective longitudinal cohort study. JTrauma. 2007;62(2):461-70. 


\section{Abedzadeh-Kalahroudi M et al.}

11. Gabbe BJ, Simpson PM, Sutherland AM, Wolfe R, Fitzgerald MC Judson R, et al. Improved functional outcomes for major trauma patients in a regionalized, inclusive trauma system. Ann Surg. 2012;255(6):1009-15.

12. Vazquez Mata G, Rivera Fernandez R, Perez Aragon A, Gonzalez Carmona A, Fernandez Mondejar E, Navarrete Navarro P. Analysis of quality of life in polytraumatized patients two years after discharge from an intensive care unit.J Trauma.1996;41(2):326-32.

13. Holbrook TL, Hoyt DB, Anderson JP. The impact of major in-hospital complications on functional outcome and quality of life after trauma.J Trauma. 2001;50(1):91-5.

14. Dimopoulou I, Anthi A, Mastora Z, Theodorakopoulou M, Konstandinidis A, Evangelou E, et al. Health-related quality of life and disability in survivors of multiple trauma one year after intensive care unit discharge. Am J Phys Med Rehabil. 2004;83(3):171-6

15. Ustun TB, Chatterji S, Kostanjsek N, Rehm J, Kennedy C, EppingJordan J, et al. Developing the World Health Organization Disability Assessment Schedule 2.0. Bull World Health Organ. 2010;88(11):815-23.

16. Hetherington H, Earlam RJ, Kirk CJ. The disability status of injured patients measured by the functional independence measure (FIM) and their use of rehabilitation services. Injury. 1995;26(2):97-101.
17. Evans SA, Airey MC, Chell SM, Connelly JB, Rigby AS, Tennant A Disability in young adults following major trauma: 5 year follow up of survivors. BMC Public Health. 2003;3:8.

18. Langley J, Lilley R, Samaranayaka A, Derrett S. Work status and disability trajectories over 12 months after injury among workers in New Zealand. N Z Med J. 2014;127(1390):53-60.

19. Holtslag HR, Post MW, van der Werken C, Lindeman E. Return to work after major trauma. Clin Rehabil. 2007;21(4):373-83.

20. Kendrick D, Vinogradova Y, Coupland C, Christie N, Lyons RA Towner EL, et al. Getting back to work after injury: the UK Burden of Injury multicentre longitudinal study. BMC Public Health. 2012;12:584.

21. Rainer TH, Yeung JH, Cheung SK, Yuen YK, Poon WS, Ho HF, et al. Assessment of quality of life and functional outcome in patients sustaining moderate and major trauma: a multicentre, prospective cohort study. Injury. 2014;45(5):902-9.

22. Holbrook TL, Hoyt DB, Anderson JP. The importance of gender on outcome after major trauma: functional and psychologic outcomes in women versus men. J Trauma. 2001;50(2):270-3.

23. Holtslag HR, van Beeck EF, Lindeman E, Leenen LP. Determinants of long-term functional consequences after major trauma.JTrauma. 2007;62(4):919-27.

24. Aitken LM, Chaboyer W, Kendall E, Burmeister E. Health status after traumatic injury.J Trauma Acute Care Surg. 2012;72(6):1702-8. 